IZA DP No. 9314

Delay of Gratification and the Role of Defaults: An Experiment with Kindergarten Children

Matthias Sutter

Levent Yilmaz

Manuela Oberauer

August 2015 


\title{
Delay of Gratification and the Role of Defaults: An Experiment with Kindergarten Children
}

\author{
Matthias Sutter \\ Levent Yilmaz \\ University of Innsbruck \\ Manuela Oberauer \\ University of Innsbruck
}

University of Cologne, University of Innsbruck and IZA

\section{Discussion Paper No. 9314 \\ August 2015}

IZA

P.O. Box 7240

53072 Bonn

Germany

Phone: +49-228-3894-0

Fax: +49-228-3894-180

E-mail: iza@iza.org

Any opinions expressed here are those of the author(s) and not those of IZA. Research published in this series may include views on policy, but the institute itself takes no institutional policy positions. The IZA research network is committed to the IZA Guiding Principles of Research Integrity.

The Institute for the Study of Labor (IZA) in Bonn is a local and virtual international research center and a place of communication between science, politics and business. IZA is an independent nonprofit organization supported by Deutsche Post Foundation. The center is associated with the University of Bonn and offers a stimulating research environment through its international network, workshops and conferences, data service, project support, research visits and doctoral program. IZA engages in (i) original and internationally competitive research in all fields of labor economics, (ii) development of policy concepts, and (iii) dissemination of research results and concepts to the interested public.

IZA Discussion Papers often represent preliminary work and are circulated to encourage discussion. Citation of such a paper should account for its provisional character. A revised version may be available directly from the author. 
IZA Discussion Paper No. 9314

August 2015

\section{ABSTRACT}

\section{Delay of Gratification and the Role of Defaults: An Experiment with Kindergarten Children*}

The ability to delay gratification has been shown to be related to higher education and income and better health status. We study in an experiment with 336 kindergarten children, aged three to six years, whether intertemporal choice behavior is malleable. In a control condition, about $50 \%$ of children prefer two rewards the next day over one reward immediately. By setting a simple default this fraction increases to more than $70 \%$, indicating that simple defaults work very successfully in promoting delay of gratification. We also find that patience increases with age and that more patient children have a lower BMI.

JEL Classification: C91, D03

Keywords: delay of gratification, intertemporal choice, default, experiment, children

Corresponding author:

Matthias Sutter

Department of Economics

University of Cologne

Albertus-Magnus-Platz

50923 Köln

Germany

E-mail: matthias.sutter@wiso.uni-koeln.de 


\section{Introduction}

The ability to delay gratification plays a major role for lifetime achievements, such as educational attainment, wealth, or health (e.g. Mischel et al., 1989, Meier and Sprenger, 2012, Sutter et al., 2013). It also reduces the risk of addictive behavior or criminal activities (Mofitt et al. (2011)), and in adolescence it promotes the social integration of teenagers in school (Castillo et al., 2011). Given the importance of the ability to delay gratification in intertemporal choice, particular attention has been paid to its development in childhood (Mischel, 2014) and how behavior in childhood relates to lifetime outcomes as adults, the results showing positive effects on education, earnings, and health (Mofitt et al., 2011, Golsteyn et al., 2014). These relationships raise the important question of whether children's choices between smaller, but sooner rewards and larger, but later rewards are malleable. Here we examine whether simple defaults can be used to promote delay of gratification. While this has been studied with adults, most prominently in the context of contributions to voluntary pension contributions (e.g. Choi et al., 2003) with defaults producing nearly 100-percent enrollment, little is known whether and how defaults work with young children. Investigating the effects of defaults in childhood seems promising, though, because in the early stages of life interventions may be very powerful, and cost efficient, instruments to promote better long-term choices, which would be beneficial both for single subjects and for society in general.

In this paper, we examine the effects of a simple default on the intertemporal choices of more than 300 preschool children, aged three to six years, in an incentivized framed field experiment. In the kindergarten years, many important behavioral and economically relevant traits such as pro-sociality and strategic reasoning evolve (Fehr et al., 2008, Sher et al., 2014, Brosig-Koch et al., 2015), which makes this period of life particularly interesting to study whether time preferences - a key trait - are malleable through simple interventions.

\section{Experimental design}

Our experiment was run in early 2014 with 336 kindergarten children in five different kindergartens, located in the cities of Schwaz, Kramsach and Völs in the Federal State of Tyrol in Austria. The project had been approved by the Tyrolean State Board of Education and by the University of Innsbruck's Internal Review Board. Parents were informed prior to the experiment about the conduct of an experimental study during regular kindergarten hours, and they could opt out their child, but no parent did. Children were also instructed that participation 
was voluntary and that they could abandon the experiment at any time. All children participated until the end.

In the experiment, all children had to choose at the beginning their most preferred item among the following set of gifts: gummy bears, crazy bands, banana chips, and lollypops. Pretests (with other children) had shown that three- to six-year olds find at least one of these gifts very attractive. After choosing their most preferred gift, we had two different treatments. In the CONTROL treatment, two items of the most preferred gift were put on a table in front of the child. This means that if a child's most preferred gift was, for example, a lollypop, then we put two lollypops in front of the child. Next to the two gifts was an empty, and unsealed envelope. The child then had to choose whether it wanted to take one item of the most preferred gift immediately as a private reward, or whether it wanted to wait and receive both items of the most preferred gift the next day. In the latter case, the experimenter put both items into the envelope and sealed it. The envelope was then marked with an ID and distributed to the child the next day.

In the DEFAULT treatment, the choice was exactly identical, except that now the two items of the most preferred gift were first put into the envelope, and the experimenter sealed it. If a child wanted to receive one item immediately, the experimenter took it out of the envelope. If the child preferred to get two items the next day, the envelope remained sealed, was then market with an ID and distributed the next day.

All children were instructed individually by student helpers on a one-to-one basis. After explaining the choice options, children had to repeat the rules, possible actions and consequences, in their own words in order to control for their understanding. In case a student helper identified problems in understanding, the helper repeated the respective parts of the rules and let the child rephrase the rules once more, up to three times in total. If a child had problems even after the third iteration, he or she was allowed to proceed to make the choice, but the data were excluded from the following analysis. In total, out of the 336 participating children, 20 had difficulties in understanding, leaving us with 316 observations. ${ }^{1}$

\footnotetext{
${ }^{1}$ Earnings from the experiment where always given into a non-transparent bag. The children were instructed to leave their bag with their presents in the wardrobe and unpack it not before they were at home. Moreover children were instructed not to talk about the experiment to each other and this was also ensured by their kindergarten teachers.
} 


\section{Results}

Figure 1 shows the proportion of children who delayed gratification and waited to get two items of the most preferred gift the next day, conditional on the treatment. In the cohort of three to four year old children (i.e., the youngest cohort in kindergarten), about $60 \%$ decided to wait in DEFAULT, while only $35 \%$ did so in CONTROL $\left(P=0.005, \chi^{2}\right.$-test). In the cohort of four to five year old children $80 \%$ in DEFAULT and 55\% in CONTROL decided to wait $(P=0.005$, $\chi^{2}$-test). The difference is smallest for the oldest cohort of preschool children, aged five to six years, although it is still 10 percentage points (85\% in DEFAULT vs. $75 \%$ in CONTROL; $P=$ $0.130, \chi^{2}$-test). If we pool all cohorts, the treatment difference is highly significant $(P=0.001$, $\chi^{2}$-test). Within each treatment, we observe that older children are significantly more patient than younger children $(P<0.005$ in each treatment, Kuzick's nonparametric test for trend).

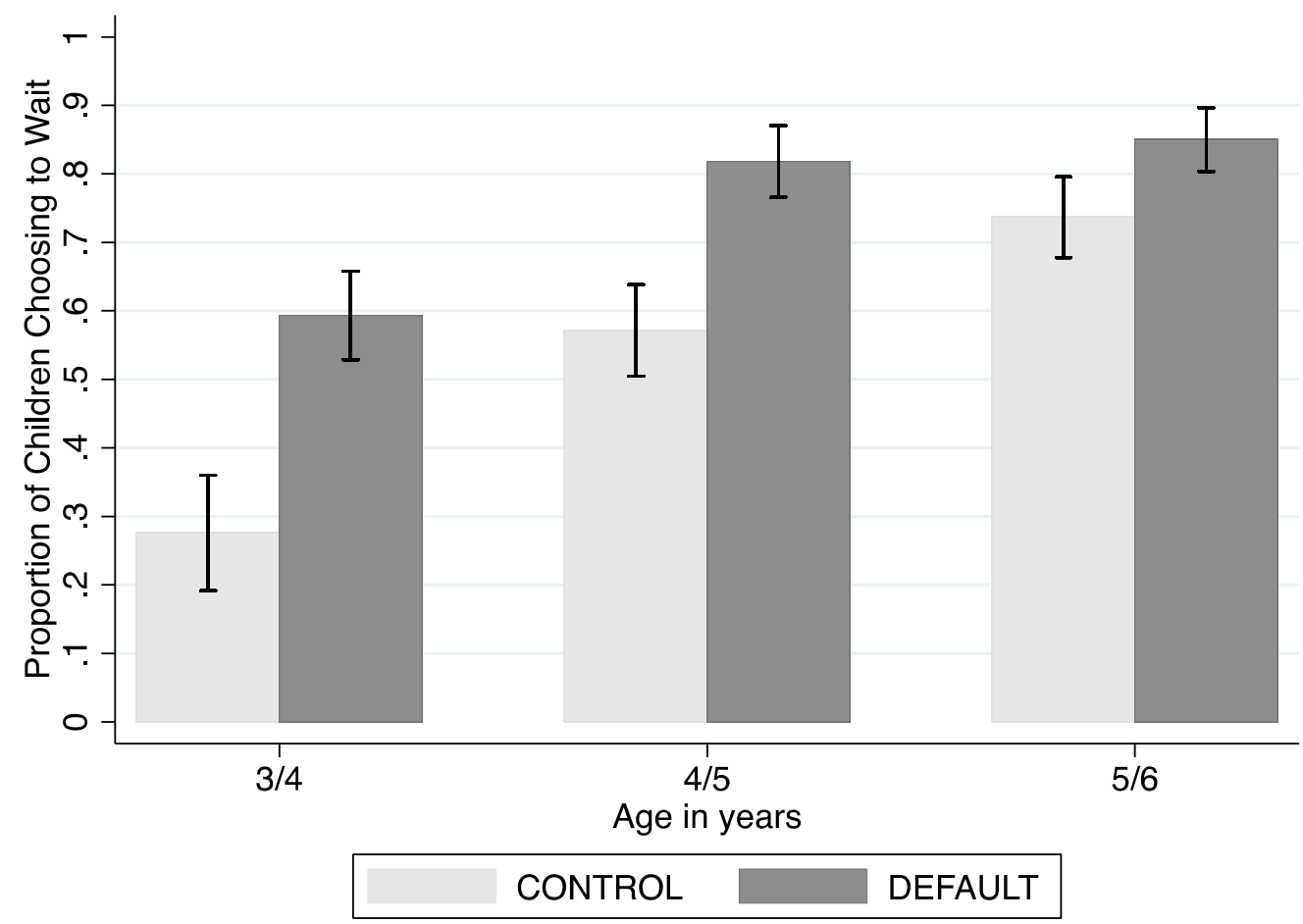

Fig. 1. Decisions of children to wait by age group and treatment. (Error Bars, Mean \pm SEM.)

These main results are confirmed by various probit regressions in Table 1 . In the most encompassing model in column (4), the effect of the DEFAULT is estimated by adding up DEFAULT and DEFAULT $\mathrm{x}$ Age and DEFAULT $\mathrm{x}$ Relative BMI, and by evaluating it for the middle age group and for the average relative BMI. The joint effect has a magnitude of 23 percentage points $(P<0.01 ; \mathrm{F}$-test). While gender has no significant effect (nor does the number 
of siblings or the fact whether a child is in afternooncare), age has a significant main effect $P<$ 0.01), which is somewhat reduced in the DEFAULT-treatment. Moreover, in the CONTROLtreatment we find an expected relation between delay of gratification and a child's BMI, normalized by gender and age cohort. Relatively more overweight children are less likely to delay gratification $(P<0.01)$. Yet, in the DEFAULT-treatment relative BMI has no overall effect (the joint effect of Relative BMI and DEFAULT x Relative BMI is insignificantly different from zero; $\mathrm{P}=0.65$, F-test). This means that the default offsets the relation between BMI and impatience.

\section{Conclusion}

The ability to delay gratification in childhood has been shown to have predictive power for success later in life, in particular with respect to educational attainment and health conditions. This is why the policy debate focuses on whether and which measures taken early in life may improve educational outcomes and subjects' health status later on in life. Here we have shown that simple defaults can help to improve the ability to delay gratification already in three- to six-years old kindergarten children. Using a default in an intertemporal choice experiment increases the likelihood of waiting for the larger, but later reward - instead of picking the smaller, but sooner reward - by about 20 percentage points. Hence, defaults do not only work with adults, but also with young children. Whether such an intervention would also work with longer delays (of weeks, or months) and not just with a short-term waiting period of one day is certainly an interesting topic for future research. Likewise, it would be interesting to study how a necessity for active decision making (by avoiding any kind of default as far as possible, thus presenting a child with both options; one piece of the most preferred good in front of the child, two pieces in the sealed envelope) would influence the intertemporal choice behavior of children. 
Table 1

Decision to wait for the next day. Probit regressions reporting marginal effects.

\begin{tabular}{lllll}
\hline \hline $\begin{array}{l}\text { Explanatory } \\
\text { Variables }\end{array}$ & \multicolumn{4}{c}{$\begin{array}{c}\text { Dependent Variable: } \\
\text { Decision to Wait }(1=\text { Yes, } 0=\text { No) }\end{array}$} \\
\hline DEFAULT (1=Yes) & 1 & 2 & 3 & 4 \\
& $0.175^{* * *}$ & $0.233^{* * *}$ & $0.371^{* * *}$ & 0.0380 \\
Age & $(0.066)$ & $(0.054)$ & $(0.067)$ & $(0.138)$ \\
& & $0.174^{* * *}$ & $0.214^{* * *}$ & $0.216^{* * *}$ \\
Gender (0=Female, 1=Male) & & $(0.019)$ & $(0.024)$ & $(0.024)$ \\
& & 0.0197 & 0.0193 & 0.0177 \\
Afternooncare (1=Yes) & & $(0.038)$ & $(0.037)$ & $(0.038)$ \\
& & -0.0245 & -0.0205 & -0.0191 \\
Siblings (1=Yes) & & $(0.072)$ & $(0.073)$ & $(0.074)$ \\
& & 0.0145 & 0.0231 & 0.0267 \\
Relative BMI & & $(0.060)$ & $(0.061)$ & $(0.062)$ \\
& & $-0.252^{* * *}$ & $-0.269^{* * *}$ & $-0.392^{* * *}$ \\
DEFAULT x Age & & $(0.076)$ & $(0.076)$ & $(0.035)$ \\
& & & $-0.0705^{* * *}$ & $-0.0711^{* * *}$ \\
DEFAULT x Relative BMI & & & $(0.020)$ & $(0.020)$ \\
& & & & $0.332^{* *}$ \\
Observations & & & & $(0.150)$ \\
Pseudo R-squared & 316 & 316 & 316 & 316 \\
AIC & 0.027 & 0.097 & 0.100 & 0.101 \\
BIC & 392.018 & 368.191 & 367.203 & 366.754 \\
& 399.529 & 383.214 & 382.226 & 381.777 \\
\hline
\end{tabular}

Notes. Probit regressions reporting marginal effects, clustered by kindergarten. Robust standard errors in parentheses.

$* * *, * *, *$ denote significance at the $1 \%, 5 \%, 10 \%$ level.

The effect of the DEFAULT-intervention in model 3 is given by DEFAULT + DEFAULT x Age. An F-test shows that the effect is positive and significantly different from zero (chi2 $=35.31$; prob $>$ chi2 $=0.000$ ). The effect of the DEFAULT-intervention in model 4 is given by DEFAULT + DEFAULT x Age + DEFAULT $x$ Relative BMI. An F-test shows that the effect is positive and significantly different from zero (chi2 $=32.73$; prob $>$ chi $2=0.000$ ).

${ }^{+}$This variable is measured by age cohort in kindergarten, where 1 is $3 / 4$ years, 2 is $4 / 5$ years and 3 is $5 / 6$ years.

${ }^{++}$This variable measures the body mass index (BMI) of a child divided by the mean BMI of the corresponding age cohort given by a data set of the World Health Organization (see

http://www.who.int/childgrowth/standards/bmi_for_age/en/). Sources for constructing the relative BMI:

Tables for girls were taken from:

http://www.who.int/entity/childgrowth/standards/sft_bfa_girls_z_2_5.pdf?ua=1 and

http://www.who.int/growthref/sft_bmifa_girls_z_5_19years.pdf?ua=1

Tables for boys were taken from:

http://www.who.int/entity/childgrowth/standards/sft_bfa boys_z_2 5.pdf?ua=1 and

http://www.who.int/entity/growthref/sft_bmifa_boys_z_ $\overline{5}$ _19years.pdf?ua $=1$ 


\section{Acknowledgments}

We wish to thank the headmasters of the participating kindergartens (Barbara Liussi, Christl Kager, Brigitte Fröhlich, Doris Friedel, Claudia Pertl, Maria Frotschnig), the parents of the involved children, as well as the children for making this study possible. Data collection was supported by Stephanie Anzengruber, Fabian Baier, Ayse Bulut-Yilmaz, Noemi Calisti, Leandra Daum, Joelle Erpelding, Melanie Malecek, Manuel Martius, Julia Möseneder, Patricia Stettner, Cagla Tamer, and Jessica Zoller. One reviewer provided very useful comments to improve the paper. Financial support from the Austrian Central Bank (OeNB JubilaeumsfondsProject 14680) is gratefully acknowledged.

\section{References}

Brosig-Koch, Janette, Heinrich, Timo, Helbach, Christoph, 2015. Exploring the capability to reason backwards: An experimental study with children, adolescents, and young adults. European Economic Review 74, 286-302.

Castillo, Marco, Ferraro, Paul J., Jordan, Jeffrey L., Petrie, Ragan, 2011. The today and tomorrow of kids: time preferences and educational outcomes of children. Journal of Public Economics 95, 1377-1385.

Choi, James J., Laibson, David, Madrian, Brigitte C., Metrick, Andrew, 2003. Optimal defaults. American Economic Review 93(2), 180-185.

Golsteyn, Bart H. H., Grönqvist, Hans, Lindahl, Lena, 2014. Adolescent time preferences predict lifetime outcomes. Economic Journal 124, 739-761.

Fehr, Ernst, Bernhard, Helen, Rockenbach, Bettina, 2008. Egalitarianism in young children. Nature 454, 1079-1083.

Meier, Stephan, Sprenger, Charles D., 2012. Time discounting predicts creditworthiness. Psychological Science 23, 56-58.

Mischel, Walter, 2014. The marshmallow test. Understanding self-control and how to master it. Bantam Press.

Mischel, Walter, Yuichi, Shoda, Rodriguez, Monica L., 1989. Delay of gratification in children. Science 244, 933-938.

Moffitt, Terrie E., Arseneault, Louise, Belsky, Daniel, Dickson, Nigel, Hancox, Robert J., Harrington, HonaLee, Houts, Renate, Poulton, Richie, Roberts, Brent W., Ross, Stephen, Sears, Malcolm R., Thomson, W. Murray, Caspi, Avshalom, 2011. A gradient of childhood 
self-control predicts health, wealth, and public safety. Proceedings of the National Acadademy of Sciences of the USA 108, 2693-2698.

Sher, Itai, Koenig, Melissa, Rustichini, Aldo, 2014. Children's strategic theory of mind. Proceedings of the National Acadademy of Sciences of the USA 111, 13307-13312.

Sutter, Matthias, Kocher, Martin G., Glätzle-Rützler, Daniela, Trautmann, Stefan T., 2013. Impatience and uncertainty: Experimental decisions predict adolescents' field behavior. American Economic Review 103, 510-531. 